\title{
The association between plasma homocysteine level and metabolic syndrome
}

\author{
A record-based study of Saudi patients attending King Abdulaziz \\ Medical City in Riyadh, Saudi Arabia
}

\author{
Abdulkarim Saeed, MBBS, Mujahid Al Shehri, MBBS, Abdulghani Al Saleb, MBBS, Fatmah Othman, PhD, \\ Mohammed Al Hazmi, MBBS, Faris Al Amri, MBBS, Mazen Ferwana, MBBS, PhD, \\ Mohammed Z. Al Yousef, MBBS, SBFM, Maha Al Turki, PhD,
}

\begin{abstract}

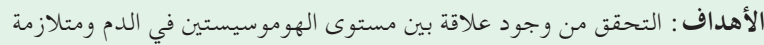

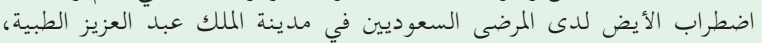
الرياض، السعودية . الابط.

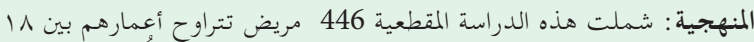



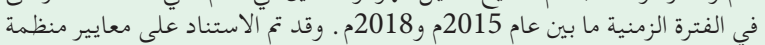

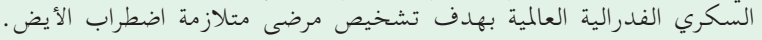

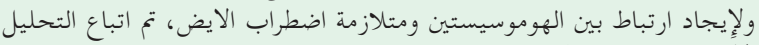

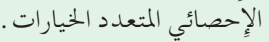

النتائج : أظهرت النتائج أن متوسط مستوى الهوموسيستين في العينة كان 10.52

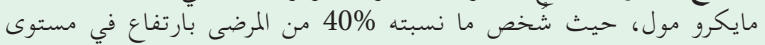

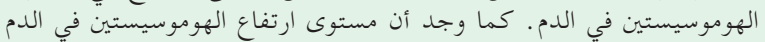



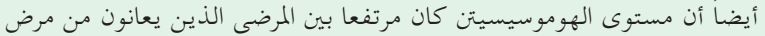

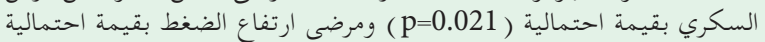

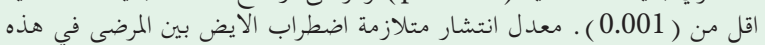

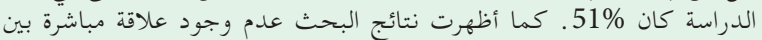

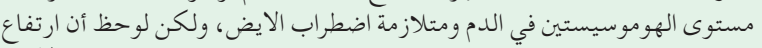

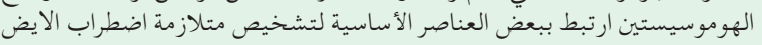
وذلك بشكل منفرد.



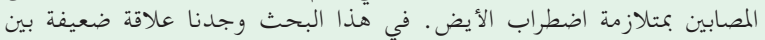

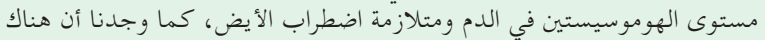

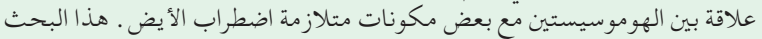

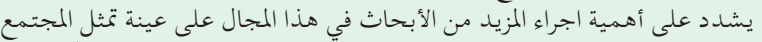

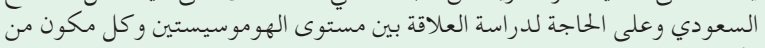

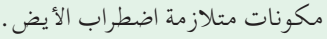

Objectives: To investigate the association between plasma homocysteine (Hcy) status and metabolic syndrome (MS) among Saudi patients attending King Abdulaziz Medical City in Riyadh, Saudi Arabia.

Methods: A record-based cross-sectional study of 446 patients was carried out. All consecutive plasma Hcy levels from 2015 to 2018 were extracted. International Diabetes Federation criteria for MS were used to classify the patients. A multivariate regression model was developed to examine the associations between plasma Hcy and MS.

Results: The mean plasma Hcy level was $10.52 \mu \mathrm{mol} / \mathrm{L}$, and $40 \%$ of the patients exhibited elevated Hcy status. Male patients had significantly elevated Hcy levels compared to female patients $(p<0.001)$. In addition, plasma Hcy levels were significantly higher in patients diagnosed with diabetes $(p=0.021)$ and hypertension $(p<0.001)$. The prevalence of MS within the study population was $51 \%$. Homocysteine levels were associated with the presence of MS independent of demographic, anthropometric and biochemical variables (odd ratio 1.018; 95\% confidence intervals 1.011 -1.047).

Conclusion: Plasma Hcy levels were elevated in $40 \%$ of the MS patients. Homocysteine had weak association with the presence of MS. Additionally, it was associated with some of its components individually. This study has raised the importance of investigating the association between Hcy status and MS among a representative sample of Saudi population. Additionally, examining possible association and interaction between Hcy level and specific component of MS is suggested to be explored in future studies.

Keywords: homocysteine, metabolic syndrome, HDL, LDL, Saudi Arabia

Saudi Med J 2020; Vol. 41 (9): 947-954 doi: 10.15537/smj.2020.9.25273

College of Medicine (Saeed, Al Shehri, Al Saleb, Al Hazmi, Al Amri), King Saud bin Abdul Aziz University for Heath Science; from College of Applied Medical Sciences (Othman, Al Turki), King Saud bin Abdul Aziz University for Heath Science; from Department of Research Unit (Othman, Al Turki, Al Yousef), King Abdullah International Medical Research Center; from the Department of Family Medicine (Ferwana), King Abdulaziz Medical City; and from the Department of Oncology (Al Yousef), King Abdulaziz Medical City, Riyadh, Kingdom of Saudi Arabia.

Received 19th May 2020. Accepted 23rd July 2020.

Address correspondence and reprint request to: Dr. Abdulkarim Saeed, College of Medicine, King Saud bin Abdulaziz University for Health Sciences, Ar Rimayah, Riyadh, Kingdom of Saudi Arabia. E-mail: saced112@ksau-hs.edu.sa

ORCID ID: https://orcid.org/0000-0002-3739-511X 
$\mathrm{R}^{\mathrm{s}}$ ecent indicators for predicting cardiovascular events have emerged in recent years, which can anticipate or are associated with the incidence of coronary heart disease (CHD). ${ }^{1}$ These indicators include B-type natriuretic peptide, lipoprotein (a), C-reactive protein and homocysteine (Hcy). ${ }^{1}$ Homocysteine is a non-protein amino acid that is synthesised from methionine obtained from either endogenous or exogenous protein degradation. ${ }^{2}$ Increased amounts of Hcy in the blood can cause diseases that affect different body systems, such as the cardiovascular system and central nervous system. ${ }^{3}$ Hyperhomocysteinemia is a risk factor for atherosclerotic vascular-endothelial injury leading to CHD. ${ }^{1}$ Metabolic syndrome (MS) is a pathophysiological condition in which multiple metabolic abnormalities exist, including central obesity, dyslipidemia, hypertension and type 2 diabetes mellitus. ${ }^{4}$ However, this group of conditions may manifest differently in a given patient, and thus the consequent pathophysiological status differs among patients. Additionally, the sequence in which signs and symptoms exhibit can vary, making it difficult to demonstrate the cause-and-effect relationship of proper management and preventive measures. ${ }^{4}$ Insulin resistance has been suggested to be the main distinguishing factor of MS, although its role in the disease remains contentious. ${ }^{5}$ Understanding the principal of how MS components work together can aid physicians to interpret the mechanisms of MS and design useful strategies for recognizing and preventing $\mathrm{CHD} .{ }^{6}$ The large number of clinical changes mimicking MS and the strong linkage of involved pathways and feedback mechanisms make it challenging to determine which events lead to the series of conditions that characterise the syndrome. ${ }^{6}$

The relationship between Hcy and MS has been the subject of many debates and studies worldwide, and many of them have reported a positive association between Hcy level and the presents of MS. ${ }^{7,8}$ In contrast to earlier findings; however, other studies have reported no evidence of an association. ${ }^{9}$ Thus, previous results have been conflicting and inconclusive. Up to now, far too little attention has been paid to explore the association between the Hcy and MS among the Saudi population. The purpose of this study, therefore, was to identify the relationship between Hcy status

Disclosure. Authors have no conflict of interests, and the work was not supported or funded by any drug company. and MS among Saudi patients attending a tertiary care hospital. It also aimed to determine the prevalence of hyperhomocysteinemia among patients diagnosed with MS according to The International Diabetes Federation (IDF) criteria.

Methods. A record-based cross-sectional study was carried out at King Abdulaziz Medical City (KAMC), Riyadh, Saudi Arabia, one of the largest tertiary hospital in middle east with capacity of more than 1100 beds. The electronic database programme for medical records was searched for any patient (inpatient, outpatients) aged 18 years old and over who had completed a laboratory test for plasma Hcy levels between the years 2015 and 2018. Demographic data (age, gender, BMI, waist circumference), lipid profiles (LDL, HDL, cholesterol, triglyceride), fasting blood glucose (FBG), or A1c levels within one month of the plasma Hcy test were collected from the patients' records. Records lacking any of the required data were excluded from the study. Four hundred and forty-six patients were enrolled in this study with completed required data. If Hcy tests had been carried out multiple times, the result of the first test was included in this study.

Metabolic syndrome was defined according to the criteria of the International Diabetes Federation (IDF). ${ }^{10}$ This definition provides a simple diagnostic and clinical tool to identify individuals at higher risk of developing type 2 diabetes and cardiovascular disease (CVD). Therefore, subjects were considered to have MS if they had central obesity (WC $>94 \mathrm{~cm}$ for males and $>80 \mathrm{~cm}$ for females) plus 2 of the following parameters: increased triglyceride $(\geq 1.7 \mathrm{mmol} / \mathrm{L})$, decreased HDL cholesterol $(>1.03 \mathrm{mmol} / \mathrm{L}$ in males and $>1.29 \mathrm{mmol} / \mathrm{L}$ in females), increased blood pressure (systolic blood pressure $[\mathrm{SBP}] \geq 130$ or diastolic blood pressure $[\mathrm{DBP}]$ $\geq 85 \mathrm{~mm} \mathrm{Hg}$ ) and elevated FBG levels $(\geq 5.6 \mathrm{mmol} / \mathrm{L})$.

The cut-off values for plasma Hcy were based on Ferri's Clinical Advisor, as follows: ${ }^{11}$ above $8.1 \mu \mathrm{mol} / \mathrm{L}$ is high in the age group of $0-30$ years, above $11.2 \mu \mathrm{mol} / \mathrm{L}$ (males) and $7.9 \mu \mathrm{mol} / \mathrm{L}$ (females) is high in the age group of 30-59 years and above $11.9 \mu \mathrm{mol} / \mathrm{L}$ is high in the age group $>59$ years. Biochemical variables of all subjects were measured in the same laboratory, following the same criteria and procedures.

Body mass index was categorized as normal (below $24.9 \mathrm{Kg} / \mathrm{m}^{2}$ ), overweight (between 25 to $29.9 \mathrm{Kg} / \mathrm{m}^{2}$ ) and obese (above $30 \mathrm{Kg} / \mathrm{m}^{2}$ ). Patients were considered hypertensive if they had SBP above 130 or DBP $>80 .{ }^{12}$ Patients were considered diabetic if they had FBG above $7.0 \mathrm{mmol} / \mathrm{L}$ or A1c above $6.5 \mathrm{mmol} / \mathrm{L} .{ }^{13}$ High total cholesterol, LDL, and triglyceride (TAG) levels were 
defined as above $5.3 \mathrm{mmol} / \mathrm{L}, 3.36 \mathrm{mmol} / \mathrm{L}$, and 1.69 mmol/L, respectively. ${ }^{14}$ In addition, HDL less than $1.55 \mathrm{mmol} / \mathrm{L}$ was considered abnormal. ${ }^{14}$

Ethical approval for this study was obtained from King Abdullah International Medical Research Center (KAIMRC)/Ministry of National Guard-Health Affairs (Reference No. RYD-18-417780-167361). The study was conducted during the period from January to April 2019.

Statistical analysis. Demographic and clinical characteristics of the study population were reported as number and percentage for categorical variables and as mean \pm standard deviation (SD) for the continuous variable if normally distributed, otherwise as median and interquartile ranges (IQR) for skewed data. The student's t-test was used to compare the mean Hcy levels with patients' clinical characteristics, and the one-way analysis of variance (ANOVA) test was used to compare the mean of more than 2 groups. Tukey's post hoc test was used to analyze significant differences, and the results were statistically significant if the $p<0.05$. Then, based on the criteria of the IDF, the study population were categorized into patients without MS and patients with MS, and we compared the clinical and biochemical characteristics among those 2 groups using the Chi-square test. The variables that showed a statistically significant association with $p<0.05$ were considered in the multivariate model. Logistic regression Conditional was carried out to estimate the odd ratio (OR) and 95\% confidence interval (95\% CI) for the potential risk of MS. All analyses were performed using Stata 12 software (StataCorp LP, College Station, TX).

Results. In total, 446 patients were included in the analysis. Table 1 demonstrates the baseline characteristics of the study population, including the anthropometric and biochemical measurements. The mean \pm SD age of the study population was $53 \pm 14$ years ( age range between 21 to 89 years ), and $51 \%$ were females. The prevalence of individuals with normal weight was $12 \%$. More than half of the patients (56\%) were overweight (BMI; $25.0-29.9 \mathrm{~kg} / \mathrm{m}^{2}$ ), and $18 \%$ were obese (BMI). Sixty-six percent (296) were diagnosed with diabetes, and $31 \%(n=140)$ were diagnosed with hypertension.

Hcy status and MS.The mean level of Hcy for the study population was $10.5 \pm 5.8 \mathrm{mmol}$. Approximately $40 \%$ of the study population exhibited elevated levels of plasma Hcy. Table 2 presents the Hcy plasma status for the whole study population. The Hcy levels of males were significantly higher than those of females $(11.3 \pm 0.3 \mathrm{mmol}$ vs. $9.3 \pm 0.3 \mathrm{mmol}$, $p<0.01)$. The mean level of Hcy was different between BMI categories $(\mathrm{F}(2,443)=17.4, p=0.003)$. A Tukey posthoc test revealed that Hcy level were statistically significantly higher in the normal category compared to the obese category $(1.3 \pm 0.8, p=0.02)$. For patients who had hypertension and diabetes mellitus, the Hcy plasma levels were higher among hypertensive $(11.9 \mathrm{mmol}$ versus $9.6 \mathrm{mmol}, p<0.001)$ and diabetic patients (10.7 versus $9.5 \mathrm{mmol}, p=0.02$ ).

The prevalence of MS within the study population was 51\%. The anthropometric and biochemical parameters of patients with and without MS are shown in Table 3 as a group analysis and in Table 4 as a linear analysis. There was a significant association between the prevalence of MS and different age categories (for trend, $p=0.007)$. In addition, there was an association between MS and different BMI categories, and the

Table 1 - General, anthropometric and biochemical characteristics of the study population $(\mathrm{n}=446)$.

\begin{tabular}{|c|c|}
\hline Variables & $\begin{array}{c}\text { All sample } \\
\text { n (\%) }\end{array}$ \\
\hline \multirow[t]{2}{*}{ Age (mean $\pm \mathrm{SD})$ range(years) } & $53.7 \pm 14$ \\
\hline & $21-89$ \\
\hline \multicolumn{2}{|l|}{ Gender } \\
\hline Female & $228(51.1)$ \\
\hline Male & $218(48.8)$ \\
\hline Waist circumference (in $\mathrm{cm})($ mean $\pm \mathrm{SD})$ & $101 \pm 12$ \\
\hline \multicolumn{2}{|l|}{ Body mass index $\left(\mathrm{kg} / \mathrm{m}^{2}\right)$} \\
\hline Normal & $55(12.3)$ \\
\hline Overweight & $252(56.5)$ \\
\hline Obese & $139(31.1)$ \\
\hline Systolic blood pressure $(\mathrm{mm} \mathrm{Hg})$ & $130(18)$ \\
\hline Diastolic blood pressure (mm Hg) & $75(10)$ \\
\hline \multicolumn{2}{|l|}{ Biochemical variables (mean $\pm \mathrm{SD}$ ) } \\
\hline Fasting blood glucose (mmol/l) & $6.5 \pm 3.0$ \\
\hline $\mathrm{A} 1 \mathrm{C}$ & $6.8 \pm 1.8$ \\
\hline HDL (mmol/l) & $1.08 \pm 0.31$ \\
\hline $\mathrm{LDL}(\mathrm{mmol} / \mathrm{l})$ & $2.82 \pm 0.96$ \\
\hline Total cholesterol $(\mathrm{mmol} / \mathrm{l})$ & $4.5 \pm 1.1$ \\
\hline Triglycerides (mmol/l) & $1.45 \pm 1.72$ \\
\hline Creatinine (mmol/l) (median, IQR) & $69.2 \pm 60-82$ \\
\hline Blood urea nitrogen $(\mathrm{mmol} / \mathrm{l})$ & $5.3 \pm 3.8$ \\
\hline Homocysteine (mmol/l) & $10.5 \pm 6.0$ \\
\hline
\end{tabular}

IQR: interquartile range, $\mathrm{A} 1 \mathrm{C}$ : hemoglobin $\mathrm{A} 1 \mathrm{c}$,

HDL: low-density lipoproteins, LDL: high-density lipoprotein 
prevalence of MS was higher in overweight and obese patients $(p<0.001)$. Fasting plasma glucose A1c levels were also higher in patients with MS than in patients without MS.

Multivariate analysis for Hcy status and MS. A logistic regression analysis was conducted to establish the association between Hcy levels and MS. Table 5 presents the analysis that included the MS as the dependent variable and Hcy as the primary independent variable alongside with the demographic,

Table 2 - Plasma homocysteine status in the study population $(\mathrm{n}=446)$.

\begin{tabular}{|c|c|c|c|}
\hline Variables & n (\%) & $\begin{array}{c}\text { Plasma } \\
\text { homocysteine } \\
\text { status }\end{array}$ & $P$-value \\
\hline Age category (years) & & & 0.287 \\
\hline$<30$ & $24 \quad(5.3)$ & $7.3 \pm 4.3$ & \\
\hline $30-59$ & $278(62.3)$ & $9.6 \pm 4.8$ & \\
\hline$>59$ & $144(32.2)$ & $12.1 \pm 5.2$ & \\
\hline Gender & & & $<0.001$ \\
\hline Female & $228(51.1)$ & $9.3 \pm 0.3$ & \\
\hline Male & $218(48.8)$ & $11.3 \pm 0.3$ & \\
\hline Body mass index $\left(\mathrm{kg} / \mathrm{m}^{2}\right)$ & & & 0.003 \\
\hline Normal & $55(12.3)$ & $11.0 \pm 6.5$ & \\
\hline Overweight & $252(56.5)$ & $10.5 \pm 5.1$ & \\
\hline Obese & $139(31.1)$ & $9.71 \pm 4.5$ & \\
\hline Hypertension & & & $<0.001$ \\
\hline No & $306(68.6)$ & $9.6 \pm 0.25$ & \\
\hline Yes & $140(31.3)$ & $11.9 \pm 0.5$ & \\
\hline Diabetes mellitus & & & 0.021 \\
\hline No & $150(33.6)$ & $9.5 \pm 0.39$ & \\
\hline Yes & $296(66.3)$ & $10.7 \pm 0.30$ & \\
\hline High total cholesterol ${ }^{*}$ & & & 0.539 \\
\hline Normal & $284(63.6)$ & $10.44 \pm 0.3$ & \\
\hline High & $162(36.3)$ & $10.1 \pm 0.41$ & \\
\hline LDL level (mmol/l) & & & 0.210 \\
\hline Normal & $244(54.7)$ & $10.6 \pm 0.31$ & \\
\hline High & $202(45.2)$ & $9.99 \pm 0.3$ & \\
\hline HDL level (mmol/l) & & & 0.450 \\
\hline Normal & $152(34.1)$ & $10.1 \pm 5.6$ & \\
\hline Low & $294(65.9)$ & $10.6 \pm 7.3$ & \\
\hline Level of triglycerides (mmo/l) & & & 0.553 \\
\hline Normal & $284(63.6)$ & $10.2 \pm 0.28$ & \\
\hline High & $162(36.3)$ & $10.5 \pm 0.48$ & \\
\hline
\end{tabular}

LDL: low-density lipoproteins, HDL: high-density lipoprotein. BMI: normal $<24.9 \mathrm{Kg} / \mathrm{m}^{2}$, overweight between 25 to $29.9 \mathrm{Kg} / \mathrm{m}^{2}$, obese $>30 \mathrm{Kg} / \mathrm{m}^{2}$. Hypertensive: $\mathrm{SBP}>130$ or DBP $>80 \mathrm{~mm} \mathrm{Hg}$. Diabetic: $\mathrm{FBG}>7.0 \mathrm{mmol} / \mathrm{L}$ or $\mathrm{Alc}>6.5 \mathrm{mmol} / \mathrm{L}$.

Cut-off values of cholesterol: $5.3 \mathrm{mmol} / \mathrm{L}$, LDL: $3.36 \mathrm{mmol} / \mathrm{L}$, HDL: $1.55 \mathrm{mmol} / \mathrm{L}$, triglycerides: $1.69 \mathrm{mmol} / \mathrm{L}$
BMI, and clinical variables. Homocysteine level was associated significantly with the presence of the MS independent of demographic anthropometric, and biochemical variables unadjusted OR 1.018 (95\% CI 1.011 - 1.047). The number of MS patients who had 2 both MS components: hypertension and diabetes mellitus were 73 patients. The results revealed that the OR for the association between Hcy levels and MS with those 2 components was $1.0595 \%$ CI 1.01-1.11).

Table 3 - Anthropometrical and biochemical parameters of patients with and without metabolic syndrome (MS).

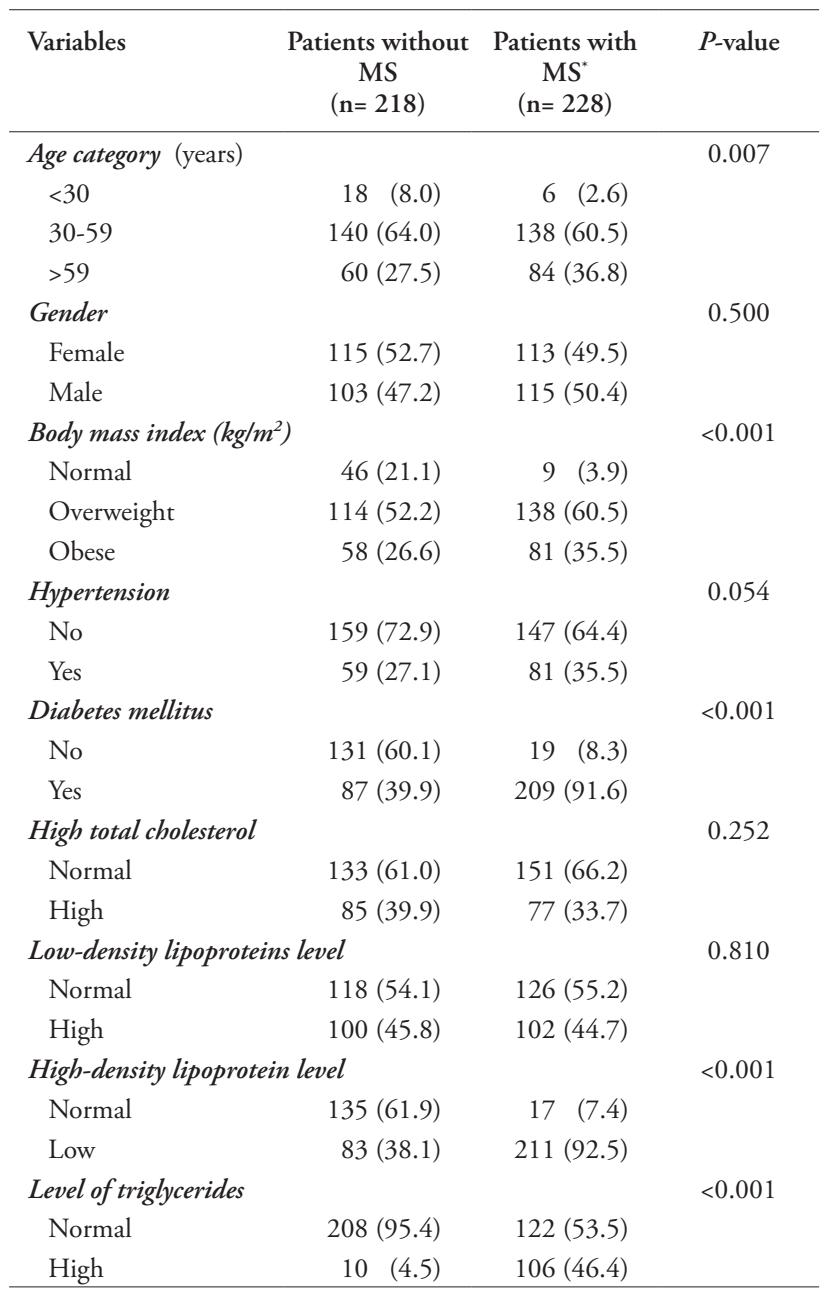

Normal BMI means below $24.9 \mathrm{Kg} / \mathrm{m}^{2}$, overweight between 25 to $29.9 \mathrm{Kg} / \mathrm{m}^{2}$ and obese above $30 \mathrm{Kg} / \mathrm{m}^{2}$. Hypertensive means systolic blood pressure $>130 \mathrm{~mm} \mathrm{Hg}$ or diastolic blood pressure $>80 \mathrm{~mm} \mathrm{Hg}$. Diabetic means fasting blood glucose $>7.0 \mathrm{mmol} / \mathrm{L}$ or hemoglobin A1c $>6.5 \mathrm{mmol} / \mathrm{L}$. Cut-off values of cholesterol $=5.3 \mathrm{mmol} / \mathrm{L}, \mathrm{LDL}=3.36$ $\mathrm{mmol} / \mathrm{L}, \mathrm{HDL}=1.55 \mathrm{mmol} / \mathrm{L}$, Triglycerides $=1.69 \mathrm{mmol} / \mathrm{L}$. *according to the IDF criteria 
Table 4 - Anthropometrical and biochemical parameters as continuous variables for patients with and without metabolic syndrome (MS).

\begin{tabular}{lccc}
\hline Variables & $\begin{array}{c}\text { Patients without MS } \\
(\mathbf{n}=218)\end{array}$ & $\begin{array}{c}\text { Patients with } \mathrm{MS}^{*} \\
(\mathbf{n}=\mathbf{2 2 8})\end{array}$ & $P_{\text {-value }}$ \\
\hline Age in year & $51.2 \pm 14.9$ & $56.2 \pm 14.6$ & 0.004 \\
Body mass index $\left(\mathrm{kg} / \mathrm{m}^{2}\right)$ & $28.9 \pm 0.4$ & $30.3 \pm 0.3$ & 0.003 \\
Waist circumference $(\mathrm{cm})$ & $99.7 \pm 0.9$ & $103.8 \pm 0.6$ & 0.004 \\
Systolic blood pressure $(\mathrm{mm} \mathrm{Hg})$ & $130.4 \pm 20.5$ & $130.2 \pm 17.2$ & 0.920 \\
Diastolic blood pressure $(\mathrm{mm} \mathrm{Hg})$ & $75.1 \pm 0.7$ & $74.9 \pm 0.7$ & 0.774 \\
Biochemical variables & & & \\
Fasting glucose $(\mathrm{mg} / \mathrm{dl})$ & $5.6 \pm 0.16$ & $7.4 \pm 0.22$ & $<0.001$ \\
A1C & $6.2 \pm 0.09$ & $7.3 \pm 0.13$ & $<0.001$ \\
HDL $(\mathrm{mg} / \mathrm{dl})$ & $1.2 \pm 0.02$ & $0.9 \pm 0.01$ & $<0.001$ \\
LDL $(\mathrm{mg} / \mathrm{dl})$ & $2.8 \pm 0.06$ & $2.7 \pm 0.06$ & 0.318 \\
Total cholesterol $(\mathrm{mg} / \mathrm{dl})$ & $4.64 \pm 0.06$ & $4.43 \pm 0.08$ & 0.049 \\
Triglycerides $(\mathrm{mg} / \mathrm{dl})$ & $1.13 \pm 0.02$ & $1.77 \pm 0.06$ & $<0.001$ \\
Creatinine $(\mathrm{mg} / \mathrm{dl})$ & $83.8 \pm 6.7$ & $87.2 \pm 4.4$ & 0.672 \\
Uric acid $(\mathrm{mg} / \mathrm{dl})$ & $4.9 \pm 0.25$ & $5.6 \pm 0.25$ & 0.063 \\
Homocysteine $(\mathrm{mmol} / \mathrm{l})$ & $10.2 \pm 0.39$ & $10.6 \pm 0.3$ & 0.411 \\
\hline
\end{tabular}

Mean \pm SD, *According to the IDF criteria

Table 5 - Multivariate logistic regression analysis estimating the odd ratio $(\mathrm{OR})$ and $95 \%$ confidence interval $(95 \% \mathrm{CI})$ for the potential risk of metabolic syndrome.

\begin{tabular}{lcc}
\hline Variables & OR & $95 \% \mathrm{CI}$ \\
\hline Homocysteine level & 1.018 & $(1.011-1.04)$ \\
Female gender & 0.752 & $(0.42-1.32)$ \\
Waist circumference & 0.98 & $(0.99-1.03)$ \\
BMI $\left(\mathrm{kg} / \mathrm{m}^{2}\right)$ & & \\
Normal & 1 & \\
Overweight & 11.55 & $(4.11-32.43)$ \\
Obese & 11.95 & $(4.07-34.83)$ \\
DM & 40.42 & $(16.63-98.74)$ \\
Hypertension & 1.42 & $(0.78-2.58)$ \\
Triglycerides & 8.21 & $(3.66-15.51)$ \\
\hline
\end{tabular}

Discussion. In this study, we found a weak association between level of Hcy in relation to increase risk of metabolic syndrome. Moreover, plasma Hcy levels were greater among MS patients who had 2 of the MS components: hypertension and diabetes mellitus. In reviewing the literature, previous studies investigating the association between Hcy and MS have reported conflicting results. Several researches have established the positive correlation between Hcy and MS in patients with atherosclerosis and hypertension. ${ }^{7,8}$ On the other hand, other studies found that Hcy was not correlated with MS but rather with some of its components. ${ }^{9}$ These inconsistencies may be attributed to the fact that plasma Hcy levels differ by age and have significant gender and ethnic dependency. ${ }^{15}$

The mean level of Hcy in our sample was $10.5 \mu \mathrm{mol} / \mathrm{L}$, which was greater than previously reported among American population in the National Health and Nutrition Examination Survey $(7.72 \mu \mathrm{mol} / \mathrm{L})$ and lower than mean value reported among Chinees population $(11.96 \mu \mathrm{mol} / \mathrm{L}){ }^{16,17}$ In the last decade, epidemiological observations have reported that Hcy status is linked to cardiovascular disease and was suggested to be an independent predictor of cardiac death among adults. ${ }^{18}$

In the current study, Hcy levels varied significantly between males and females. This difference could be explained by Hcy metabolism, which occurs mainly through 2 pathways. ${ }^{19}$ One is by trans-sulfuration, where Hcy is converted to cysteine by the presence of vitamin B6 as a cofactor. ${ }^{19}$ The second pathway is methylation, depending on the availability of vitamin B12 and folate. ${ }^{19}$ Females have greater Hcy reflux through the trans-sulfuration pathway, which in turn 
lowers Hcy levels. ${ }^{20}$ Meanwhile, in males, creatinine is needed to build muscular mass. The biosynthesis of creatine requires s-adenosyl methionine to be converted to s-adenosyl Hcy, a precursor of Hcy. ${ }^{21}$ The need for Hcy and the lower reflux through the trans-sulfuration pathway could explain the higher Hcy levels in males comparing to females. ${ }^{22}$ The mean level of Hcy among hypertensive patients was higher than that of normotensive patients. These results are similar to those observed by Biswas et $\mathrm{a}^{23}$ among hypertension patients. Furthermore, homocysteine status was reported to be an important indicator of hypertension and that the blood pressure increased with increasing homocysteine levels. ${ }^{24}$ It is proposed that the levels of folate and Hcy play a role in endothelium-dependent vasodilation, and any disturbance to these may contribute directly or indirectly to the development of hypertension after the exhibition of endothelial dysfunction. ${ }^{25}$

Our study showed that patients with diabetes have high Hcy levels when compared to non-diabetics. This finding broadly supports the work of other studies linking hyperhomocysteinemia with diabetes and insulin resistance. ${ }^{26-30}$ Yang et $\mathrm{al}^{30}$ found that, even after the adjustment of several important co-factors, Hcy levels were significantly associated with elevated fasting insulin levels. An experimental trial with rat models attempted to explore the metabolic characteristics of homocysteine levels reported that high insulin levels affect cystathionine $\beta$-synthase, 5, 10-methylene tetrahydrofolate reductase and methionine synthase enzymes, which in turn has an impact on Hcy metabolism. ${ }^{31}$

Saudi Arabia has a high prevalence of diabetes and obesity and other features of MS compared to other countries. ${ }^{32,33}$ The incidence of MS often parallels the incidence of diabetes and the incidence obesity. In this study, the prevalence of MS was $51 \%$, which is greater than the previously reported among Asian population $(12-37 \%)$ and European population (12-26\%). ${ }^{34}$ Recent meta-analysis review investigated the prevalence of MS and reported that the prevalence rate in the Gulf Corporation Council countries (GCC) was greater than reported among other regions such as Europe, Latin American, Asia and Africa. ${ }^{35}$ These results are likely to be related to tremendous changes in dietary habits and lifestyle in GCC over the past few decades.

The findings in this study showed that the age plays an important role in MS. Specifically, as patients get older, they are more likely to develop MS, with the peak prevalence occurring in patients in the fifth and sixth decades of life and declining afterward. Different aetiologies could be responsible for the link between age and MS, such as hormonal changes, central obesity and insulin resistance. ${ }^{36} \mathrm{~A}$ further explanation for this association could be the increase in the rate of separate features of MS (hypertension and diabetes) with age in Saudi Arabia. ${ }^{37}$ Another important finding is related to BMI. The study showed an association between MS and different BMI categories, with a higher MS prevalence among overweight and obese patients. In accordance with the present results, a previous study demonstrated that both male and female MS patients had elevated BMI's. ${ }^{38}$ However, in that study, waist circumference was a stronger predictor of MS than BMI due to abdominal obesity, which is linked strongly to cardiovascular events.

Additionally, our results showed that uric acid levels were greater in patients with MS than in those without MS. Although uric acid levels are not among any of provided MS criteria's, the incidence of MS and elevated level of uric acid was reported in several studies. Our finding is consistent with other studies that showed an association between uric acid and dyslipidemia features (low HDL and high TAG), which are components of MS. ${ }^{39}$ The atherogenic index of plasma (AIP), which takes into account not just HDL cholesterol but also TAG, showed a significant relationship between high uric acid levels and increased TAG plasma and decreased HDL levels. ${ }^{39}$ The same study demonstrated contrary results regarding insulin resistance, another parameter of MS, as there was a weak correlation with uric acid; however, this relationship is still debated. ${ }^{39}$ Animal and clinical studies showed that elevated levels of uric acid may have a significant role in the development of MS. ${ }^{40}$ Conversely, in a 10-year follow-up study of adults, high uric acid concentrations did not influence the occurrence of type 2 diabetes in males and females. ${ }^{41}$

Study limitations. In the present study, several limitations should to be considered. First, the observational nature of the study made it impossible to account for all unmeasured confounders that might have affected the relation between Hcy and MS such as vitamin B12 and folic acid. Second, we limited our analysis to patients with complete data, which could have led to selection bias. Our study sample was also restricted to adult patients attending single medical institution in Riyadh. Therefore, this limit the possibility to extend our findings to a more general context. However, the aim of this study was to examine the association between Hcy levels and MS, and therefore we needed to identify patients with complete sets of variables. Another limitation in this study is related to dealing with the Hcy level as a continuous variable 
in the assessment of exposure-outcome relationships, which may not provide a clear view. However, categorization of the Hcy level into groups will depend on data-driven cut-points to define the categories, which leads to difficulty comparing the reported results with other studies. Moreover, further research should be undertaken to investigate the association between homocysteine status and MS among a representative sample of Saudi population. Despite these limitations, given the importance of studies on the MS among Saudis and the association with homocysteine status, our results represent an important contribution in understanding this association and MS-related comorbidities. Second, in comparison to other studies that applied MS criteria that depend on insulin resistance, we used IDF criteria, which depend on central obesity, and it was the most recent version.

In conclusion, plasma Hcy levels were elevated in $40 \%$ of the MS patients. Homocysteine had significant weak association with the presence of MS. Moreover, it was associated with some of its components individually. This study has raised the importance of investigating the association between Hcy status and MS among a representative sample of Saudi population. Additionally, examining possible association and interaction between Hcy level and specific component of MS is suggested to be explored in future studies.

Acknowledgment. Special thanks are due to the King Abdulaziz Medical City (KAMC), National Guard Health Affairsl Ministry of National Guard, Riyadh, Saudi Arabia for providing us with all essential data related to plasma homocysteine analysis between 2015 and 2018. Also we would like to thank the English academic proofreading SCRIBENDI (https://www.scribendi.com) for English language editing.

\section{References}

1. Zendjabil M, Abbou O, Chellouai Z. Association between metabolic ndrome and hyperhomocysteinemia in an Algerian population. Ann Pharm Fr 2017; 75: 54-58.

2. Škovierová H, Vidomanová E, Mahmood S, Sopková J, Drgová A, Červeňová $\mathrm{T}$, et al. The molecular and cellular effect of homocysteine metabolism imbalance on human health. Int J Mol Sci 2016; 17: 1733.

3. Zhao MJ, Yang YH, Zhou SJ, Yuan D, Lu WH, Xiao-wei L et al. Serum homocysteine and metabolic syndrome in middle-aged and elderly men. Zhonghua Nan Ke Xue 2016; 22: 138-142.

4. Saklayen MG. The global epidemic of the metabolic syndrome. Curr Hypertens Rep 2018; 20: 12.

5. Gluvic Z, Zaric B, Resanovic I, et al. Link between metabolic syndrome and insulin resistance. Curr Vasc Pharmacol 2017; 15: 30-39.
6. Gurka MJ, Guo Y, Filipp SL, DeBoer MD. Metabolic syndrome severity is significantly associated with future coronary heart disease in type 2 diabetes. Cardiovasc Diabetol 2018; 17: 17.

7. Catena C, Colussi G, Nait F, Capobianco F, Sechi L. Elevated homocysteine levels are associated with the metabolic syndrome and cardiovascular events in hypertensive patients. Am J Hypertens 2015; 28: 943-950.

8. Sreckovic B, Sreckovic VD, Soldatovic I, et al. Homocysteine is a marker for metabolic syndrome and atherosclerosis. Diabetes Metab Syndr 2017; 11: 179-182.

9. Zendjabil M, Abbou O, Chellouai Z. Association entre syndrome métabolique et hyperhomocystéinémie dans une population algérienne [Association between metabolic syndrome and hyperhomocysteinemia in an Algerian population]. Ann Pharm Fr 2017; 75: 54-58.

10. Alberti KG, Zimmet P, Shaw J. The metabolic syndrome-a new worldwide definition. The Lancet 2005; 366: 1059-1062.

11. Ferri FF, editor. Laboratory tests and interpretation of results. Ferri's Clinical Advisor. 1st ed. USA: Elsevier Mosby; 2012.

12. Whelton PK, Carey RM, Aronow WS, Casey DE Jr, Collins KJ, Dennison Himmelfarb C, et al. 2017 ACC/AHA/AAPA/ABC/ ACPM/AGS/APhA/ASH/ASPC/NMA/PCNA Guideline for the Prevention, Detection, Evaluation, and Management of High Blood Pressure in Adults: Executive Summary: A Report of the American College of Cardiology/American Heart Association Task Force on Clinical Practice Guidelines. Hypertension 2018; 71: 1269-1324.

13. American Diabetes Association. Type 2 diabetes. [cited 2019]. Available from: https://www.diabetes.org/a1c/diagnosis

14. Whelton PK, Carey RM, Aronow WS, Casey DE Jr, Collins KJ, Dennison Himmelfarb C, et al. 2017 ACC/AHA/AAPA/ABC/ ACPM/AGS/APhA/ASH/ASPC/NMA/PCNA Guideline for the Prevention, Detection, Evaluation, and Management of High Blood Pressure in Adults: Executive Summary: A Report of the American College of Cardiology/American Heart Association Task Force on Clinical Practice Guidelines. Hypertension 2018; 71: 1269-1324.

15. Guo S, Pang H, Guo H, Zhang M, He J, Yan Y, et al. Ethnic differences in the prevalence of high homocysteine levels among low-income rural Kazakh and Uyghur adults in far western China and its implications for preventive public health. Int J Environ Res Public Health 2015; 12: 5373-5385.

16. Omoike OE, Paul TK, Ridner SL, Awasthi M, Harirforoosh S, Mamudu HM. Association between smoking status and homocysteine levels and possible effect modification by cholesterol and oestradiol. Biomarkers 2020; 25: 126-130.

17. Momin M, Fan F, Li J, Qin X, Jia J, Qi L, et al. Associations of plasma homocysteine levels with peripheral systolic blood pressure and noninvasive central systolic blood pressure in a community-based Chinese population. Sci Rep 2017; 7: 6316.

18. Ganguly P, Alam SF. Role of homocysteine in the development of cardiovascular disease. Nutr J 2015; 14: 6 .

19. Kumar A, Palfrey HA, Pathak R, Kadowitz PJ, Gettys TW, Murthy SN. The metabolism and significance of homocysteine in nutrition and health. Nutr Metab (Lond) 2017; 14: 78.

20. Barroso M, Handy D, Castro R. The link between hyperhomocysteinemia and hypomethylation: Implications for cardiovascular disease. Journal of Inborn Errors of Metabolism and Screening 2017; 5: e160024.

21. Amin HK, El-Sayed MI, Leheta OF. Homocysteine as a predictive biomarker in early diagnosis of renal failure susceptibility and prognostic diagnosis for end stages renal disease. Ren Fail 2016; 38: 1267-1275. 
22. Cohen E, Margalit I, Shochat T, Goldberg E, Krause I. Gender differences in homocysteine concentrations, a population-based cross-sectional study. Nutr Metab Cardiovasc Dis 2019; 29: 9-14.

23. Biswas S, Haque R, Uddin N, Saha A, Sultan K, Khondker, et al. Raised serum homocysteine level is associated with hypertension. Bangladesh Journal of Medical Biochemistry 2019; 11: 22-25.

24. Guoqiang Gu, Ruitao Liu, Yaqing Zhou, Ying Zhang, Wei Cui. Correlation between homocysteine levels and 24-hambulatory blood pressure variability in Chinese hypertensive patients. Int J Clin Exp Med 2016; 9: 11715-11722.

25. Lai WK, Kan MY. Homocysteine-induced endothelial dysfunction. Ann Nutr Metab 2015; 67: 1-12.

26. Feng $\mathrm{X}, \mathrm{Xu}$ Y. Hyperhomocysteinemia as a metabolic risk factor for glucose intolerance among high-risk groups of chinese adults. Med Sci Monit 2017; 23: 2775-2781.

27. Platt DE, Hariri E, Salameh P, Merhi M, Sabbah N, Helou M, et al. Type II diabetes mellitus and hyperhomocysteinemia: a complex interaction. Diabetol Metab Syndr 2017; 9: 19.

28. Gong T, Wang J, Yang M, Shao Y, Liu J, Wu Q, et al. Serum homocysteine level and gestational diabetes mellitus: A metaanalysis. J Diabetes Investig 2016; 7: 622-628.

29. Ala OA, Akintunde AA, Ikem RT, Kolawole BA, Ala OO, Adedeji TA. Association between insulin resistance and total plasma homocysteine levels in type 2 diabetes mellitus patients in south west Nigeria. Diabetes Metab Syndr 2017; 11 Suppl 2: S803-S809.

30. Yang N, Yao Z, Miao L, Liu J, Gao X, Fan H, et al. Novel clinical evidence of an association between homocysteine and insulin resistance in patients with hypothyroidism or subclinical hypothyroidism. PLoS One 2015; 10: e0125922.

31. Li D, Liu HX, Fang YY, et al. Hyperhomocysteinemia in polycystic ovary syndrome: decreased betaine-homocysteine methyltransferase and cystathionine $\beta$-synthase-mediated homocysteine metabolism. Reprod Biomed Online 2018; 37: 234-241.
32. Meo SA. Prevalence and future prediction of type 2 diabetes mellitus in the Kingdom of Saudi Arabia: A systematic review of published studies. J Pak Med Assoc 2016; 66: 722-725.

33. Al-Hussaini A, Bashir MS, Khormi M, et al. Overweight and obesity among Saudi children and adolescents: Where do we stand today?. Saudi J Gastroenterol 2019; 25: 229-235.

34. Ranasinghe P, Mathangasinghe Y, Jayawardena R, Hills AP, Misra A. Prevalence and trends of metabolic syndrome among adults in the Asia-Pacific region: a systematic review. $B M C$ Public Health 2017; 17: 101.

35. Shin S, Jee H. Prevalence of metabolic syndrome in the Gulf Cooperation Council countries: meta-analysis of cross-sectional studies. J Exerc Rehabil 2020; 16: 27-35.

36. Devers MC, Campbell S, Simmons D. Influence of age on the prevalence and components of the metabolic syndrome and the association with cardiovascular disease. BMJ Open Diabetes Res Care 2016; 4: e000195.

37. Al-Rubeaan K, Al-Manaa H, Khoja T, Ahmad N, Al-Sharqawi A, Siddiqui K, et al. The Saudi Abnormal Glucose Metabolism and Diabetes Impact Study (SAUDI-DM). Ann Saudi Med 2014; 34: 465-475.

38. Al-Rubean K, Youssef AM, AlFarsi Y, Al-Sharqawi AH, Bawazeer N, AlOtaibi MT, et al. Anthropometric cutoff values for predicting metabolic syndrome in a Saudi community: from the SAUDI-DM study. Ann Saudi Med 2017; 37: 21-30.

39. Cibičková L, Langová K, Vaverková H, Kubíčková V, Karásek D. Correlation of uric acid levels and parameters of metabolic syndrome. Physiol Res 2017; 66: 481-487.

40. Kanbay M, Jensen T, Solak Y, Le M, Roncal-Jimenez C, Rivard $\mathrm{C}$, et al. Uric acid in metabolic syndrome: From an innocent bystander to a central player. Eur J Intern Med 2016; 29: 3-8.

41. Sun HL, Pei D, Lue KH, Chen YL. Uric acid levels can predict metabolic syndrome and hypertension in adolescents: a 10-year longitudinal study. PloS One 2015; 10: e0143786. 